\title{
Influence of some methylated hepatocarcinogenesis- related genes on the response to antiviral therapy and development of fibrosis in chronic hepatitis $\mathrm{C}$ patients
}

\author{
Waleed Seif Eldin Mohamed Mostafa, ${ }^{1,2}$, Mohammed Hassan Saiem Al-Dahr ${ }^{2}$, Dalia Abdel Hamid Omran ${ }^{3}$, \\ Zeinab Fathy Abdullah', Suzan Hamdy Elmasry ${ }^{4}$, and Mohamed Nabil Ibrahim ${ }^{2}$ \\ 'Virology and Immunology Unit, Department of Cancer Biology, National Cancer Institute, Cairo University, Cairo, Egypt; ${ }^{2}$ Department \\ of Clinical Laboratory Sciences, College of Applied Medical Sciences, Jouf University, Al-Qurayyate, Kingdom of Saudi Arabia; ${ }^{3}$ De- \\ partment of Endemic Medicine and Hepatogastroenterology, Faculty of Medicine, Cairo University, Cairo, Egypt; ${ }^{4}$ Department of \\ Biochemistry, Ibn Sina National College for Medical Studies, Jeddah, Kingdom of Saudi Arabia
}

Background/Aims: Epigenetics involved in multiple normal cellular processes. Previous research have revealed the role of hepatitis $\mathrm{C}$ virus infection in accelerating methylation process and affecting response to treatment in chronic hepatitis patients. This work aimed to elucidate the role of promoter methylation (PM) in response to antiviral therapy, and its contribution to the development of fibrosis through hepatocarcinogenesis-related genes.

Methods: A total of 159 chronic hepatitis Egyptian patients versus 100 healthy control group were included. The methylation profile of a panel 9 genes (SFRP1, p14, p73, APC, DAPK, RASSF1A, LINE1, O6MGMT, and p16) was detected in patients' plasma using methylation-specific polymerase chain reaction (MSP).

Results: Clinical and laboratory findings were gathered for patients with combined pegylated interferon and ribavirin antiviral therapy. Regarding the patients' response to antiviral therapy, the percentage of non-responders for APC, O6MGMT, RASSF1A, SFRP1, and p16 methylated genes were significantly higher versus responders $(P<0.05)$. Of the 159 included patients, the most frequent methylated genes were SFRP1 (102/159), followed by p16 (100/159), RASSF1A (98/159), then LINE1 (81/159), P73 (81/159), APC (78/159), DAPK (66/159), O6MGMT (66/159), and p14 (54/159). A total of 67/98 (68.4\%) cases of RASSF1A methylated gene $(P=0.0 .024)$, and $62 / 100(62 \%)$ cases of $P 16$ methylated gene $(P=0.03)$ were associated with mild-degree fibrosis.

Conclusions: To recapitulate, the PM of SFRP1, APC, RASSF1A, O6MGMT, and p16 genes increases in chronic hepatitis C patients, and can affect patients' response to antiviral therapy. The RASSF1A and P16 genes might have a role in the distinction between mild and marked fibrosis. (Clin Mol Hepatol 2020;26:60-69)

Keywords: Peginterferon alfa-2b; Ribavirin; Fibrosis; Hepatitis C, Chronic

\section{Study Highlights}

- We detected 9 hepatocarcinogenesis-related genes in chronic HCV cases.

- SFRP1, APC, RASSF1A, O6MGMT \& P16 genes can be used as predictors of antiviral response.

- RASSF1A \& p16 methylated genes might be helpful in predicting fibrosis stage.

\section{Abbreviations:}

Ab, antibody; ALT, alanine aminotransferase; BMI, body mass index; $C H C$, chronic hepatitis $C_{;}$GGT, gamma glutamyltransferase; $\mathrm{HBsAg}$, hepatitis B surface antigen; HBV, hepatitis B virus; HCC, hepatocellular carcinoma; HCV, hepatitis C virus; HIV, human immunodeficiency virus; M, methylated; MSP, methylation-specific polymerase chain reaction; $\mathrm{PCR}$, polymerase chain reaction; $\mathrm{PM}$, promoter methylation; SVR, sustained virological response; UM, unmethylated; WHO, World Health Organization
Corresponding author : Waleed Seif Eldin Mohamed Mostafa

Cancer Biology (Virology \&Immunology) at Virology and Immunology

Unit, Department of Cancer Biology, National Cancer Institute, Cairo University, Kasr El-Aini Street, Fom El-Khalig, NCl, Cairo 11796, Egypt

Tel: +2-01097411599, Fax: +202-2365-9711

E-mail:waleed.seif@nci.cu.edu.eg orwseifeldin@ju.edu.sa

https://orcid.org/0000-0002-8698-317X 


\section{INTRODUCTION}

Chronic liver disease may be defined as a disease of the liver that lasts over a period of 6 months. It comprises liver pathologies such as chronic hepatitis, liver cirrhosis, and hepatocellular carcinoma.' Hepatitis $\mathrm{C}$ virus (HCV) infection is one of the causes that associated with chronic liver diseases. Infections with the HCV are pandemic, and the World Health Organization (WHO) estimates a world-wide prevalence of $3 \%$. In Middle Europe, about $1 \%$ of the population is infected, mostly with genotype 1 (85\% in Austria). In developing countries, chronic hepatitis $\mathrm{C}(\mathrm{CHC})$ is the most prominent cause for liver cirrhosis, hepatocellular carcinoma and liver transplantation. ${ }^{2}$

Ribavirin/pegylated-interferon combination therapy is currently the most effective treatment for hepatitis $C$ infection. Clearance of this HCV can be predicted by a sustained virological response (SVR). ${ }^{3}$ The main predictors of SVR are HCV genotype, stage of fibrosis, baseline HCV RNA levels, the dose and duration of therapy, IL28B polymorphism, body mass index (BMI), age, insulin resistance, gender, the levels of alanine aminotransferase (ALT), gamma glutamyl-transferase (GGT), and co-infection with human immunodeficiency virus (HIV) or other hepatotropic virus. ${ }^{4}$ Many authors have found that different types of cancer, including hepatocellular carcinoma (HCC), show distinct DNA methylation profiles; suggesting the existence of cancer-type specific methylation signatures. ${ }^{5}$ Others have shown that the presence of hepatitis viruses, especially HCV, could play a role in accelerating the methylation process which is involved in $\mathrm{HCC}$ development, potentiate the progression of HCV related liver disease and affect its response to treatment. ${ }^{6,7}$

Molecular pathogenesis of hepatocarcinogenesis still unclear. However, it has been revealed that epigenetic changes, especially global DNA hypomethylation concomitant with locus-specific DNA hypermethylation in gene promoters, plays vital roles in carcinoma progression. ${ }^{8,9}$ DNA methylation markers could be utilized to detect human cancers in blood, plasma, secretion, or exfoliated cytology specimens and predict the risk of cancer development. ${ }^{10,11}$ Thus, cell free DNA circulating in plasma of chronic liver disease patients may represent a promising non-invasive alternative for HCC screening and monitoring. Progression from chronic hepatic inflammation to the fibrotic/cirrhotic stage is supported by numerous core pathways, observed in other fibrotic diseases, as well as tissue- or injury-specific pathways that are only activated in particular conditions. ${ }^{12,13}$

Therefore, the present work was applied to verify the previous results, ${ }^{7,14}$ and elucidate the role of promoter methylation (PM) in the response to antiviral therapy, and its contribution to the development of fibrosis using some hepatocarcinogenesis-related genes such as SFRP1, p14, p73, APC, DAPK, RASSF1A, LINE1, O6MGMT, and p16.

\section{MATERIALS AND METHODS}

\section{Patient specimens}

This study was done on 159 Egyptian patients with chronic genotype 4 hepatitis C in addition to 100 healthy control group. These patients were eligible for ribavirin/pegylated interferon combination therapy. Selection of patients was based on clinical and histological examinations. Inclusion criteria were morphologic evidence of chronic hepatitis, normal renal function (normal creatinine level), normal prothrombin time, elevated hepatic function (elevated bilirubin, aspartate aminotransferase and ALT levels), normal cardiac enzymes, HIV-antibody (Ab) negative by ELISA, hepatitis $B$ surface antigen (HBSAg) negative by ELISA and hepatitis $B$ virus (HBV) DNA negative by polymerase chain reaction $(P C R)$, and anti-HCV positive by ELISA. Informed consents were obtained from all the participants enrolled in the study, which was performed in accordance with the declaration of Helsinki, local and national laws.

\section{Laboratory investigations}

They were done, and HCV RNA was quantified using quantitative real time $P C R^{15}$ at baseline, after $12,24,48$, and 72 weeks of anti-viral therapy. Histological examination was done on core needle biopsies to determine the grade of necro-inflammation and the stage of fibrosis according to the Metavir scoring system prior to treatment. For the steatosis assessment tool, it was confirmed histologically, and expressed as \% values of fatty changed. Also, it was checked by abdominal ultrasonography, each criterion of none, minimal, mild, and moderate steatosis was demonstrated in Table 1. Clinical and laboratory follow up were done for every patient to report any adverse side effects and treatment response according to interferon treatment guidelines.

\section{DNA extraction}

DNA was extracted from patient's plasma before receiving riba- 
Table 1. Clinico-pathological features of 159 Egyptian patients with chronic genotype 4 hepatitis C

\begin{tabular}{|c|c|c|c|c|}
\hline Variable & Responders ( $n=81)$ & Non-responders $(n=78)$ & Total & $P$-value \\
\hline Age (years) & $37.8 \pm 6.8$ & $40.8 \pm 9.0$ & $38.1 \pm 8.9$ & 0.462 \\
\hline Sex, M/F & $75 / 12$ & $60 / 12$ & $135 / 24$ & 0.805 \\
\hline BMI $\left(\mathrm{kg} / \mathrm{m}^{2}\right)$ & $26.51 \pm 3.86$ & $70.06 \pm 11.79$ & $49.7 \pm 8.9$ & $0.03^{*}$ \\
\hline WBC $\left(2.5-30.0 \times 10^{3} / \mathrm{mm}^{3}\right)$ & $6.5 \pm 2.4$ & $6.3 \pm 1.7$ & $6.4 \pm 2.1$ & 0.149 \\
\hline Hemoglobin (9-17 gm/dL) & $14.2 \pm 1.5$ & $14.2 \pm 1.7$ & $14.2 \pm 1.6$ & 0.641 \\
\hline Platelets $\left(100-600 \times 10^{3} / \mathrm{mm}^{3}\right)$ & $188.1 \pm 63.6$ & $209.3 \pm 65.7$ & $197.7 \pm 64.8$ & 0.683 \\
\hline Albumin (3.5-5.5 gm/dL) & $4.2 \pm 0.4$ & $4.1 \pm 0.3$ & $4.2 \pm 0.5$ & 0.207 \\
\hline Total bilirubin (0.1-1.2 mg/dL) & $0.78 \pm 0.21$ & $0.80 \pm 0.33$ & $0.79 \pm 0.27$ & 0.116 \\
\hline $\operatorname{ALT}(0-42 \mathrm{IU} / \mathrm{L})$ & $101.11 \pm 181.11$ & $121.35 \pm 401.73$ & $118.11 \pm 231.11$ & 0.617 \\
\hline AST (0-42 IU/L) & $52.30 \pm 30.23$ & $62.35 \pm 32.73$ & $57.23 \pm 31.59$ & 0.155 \\
\hline ALP (0-290 IU/L) & $124.81 \pm 72.43$ & $107.81 \pm 64.30$ & $116.47 \pm 68.45$ & 0.406 \\
\hline AFP (0-10 ng/mL) & $5.3 \pm 7.3$ & $7.2 \pm 10.4$ & $10.1 \pm 1.5$ & 0.346 \\
\hline HCV viral load (IU/mL) & $193.000 \pm 108.000$ & $338.000 \pm 237.000$ & $244.231 \pm 101.000$ & 0.789 \\
\hline \multicolumn{5}{|l|}{ Fibrosis } \\
\hline Mild to moderate (F1 \& F2) & $63(77.7)$ & $57(73.1)$ & $120(75.5)$ & $\begin{array}{c}0.03^{*} \\
(F 1 \& F 2 \text { vs. F3 \& F4) }\end{array}$ \\
\hline Marked (F3 \& F4) & $18(22.3)$ & $21(26.9)$ & $39(24.5)$ & \\
\hline Necroinflammatory activity & & & & $0.01^{*}(\mathrm{~A} 1 \& \mathrm{~A} 2$ vs. $\mathrm{A} 3$ \& $\mathrm{A} 4)$ \\
\hline$A 1 \& A 2$ & 69 (85.1) & $72(92.3)$ & $141(88.6)$ & \\
\hline $\mathrm{A} 3$ \& A4 & $12(14.9)$ & $6(7.7)$ & $18(11.4)$ & \\
\hline Steatosis & & & & 0.459 \\
\hline None & $18(66.7)$ & $9(33.3)$ & $27(17)$ & \\
\hline Minimal & $9(42.9)$ & $12(57.1)$ & $21(13.2)$ & \\
\hline Mild & $47(54)$ & $39(44.8)$ & $87(54.7)$ & \\
\hline Moderate & $12(50)$ & $12(50)$ & $24(15.1)$ & \\
\hline
\end{tabular}

Values are presented as mean \pm standard deviation or number (\%).

M, male; F, female; BMI, body mass index; WBC, white blood cells; ALT, alanine aminotransferase; AST, aspartate aminotransferase; ALP, alkaline phosphatase; AFP, a-fetoprotein; HCV, hepatitis C virus.

virin/pegylated interferon combination therapy, according to the previously published protocol. ${ }^{16}$ DNA was extracted through a phenol/chloroform treatment. Briefly, equal volume of buffer equilibrated phenol (pH 7.0-7.5) was added to samples and vortexed. The upper aqueous layer was removed with a "cut down" pipette tip, and an equal volume of phenol/chloroform (1:1) was then added to the aqueous supernatant and vortexed. The upper aqueous layer was removed again in a similar fashion, and an equal volume of chloroform/isoamyl (24:1) was then added and vortexed. Sodium acetate (3 M) (pH 4.7-5.2) was added to the aqueous supernatant, followed with ice-cold ethanol. Samples were then incubated overnight at $-8^{\circ} \mathrm{C}$. After decantation of the liquid, the DNA pellet was recovered and dissolved in sterile wa- ter. The purity and integrity of the DNA was confirmed by carrying out $\beta$-actin gene amplification.

\section{Bisulphate conversion and methylation-specific polymerase chain reaction (MSP)}

After DNA extraction, it was subjected to bisulfite treatment using EZ DNA methylation kit that uses $300 \mathrm{ng}$ of the extracted nucleic acid. This was followed by MSP using the primer sequences and the methylation-specific PCR conditions illustrated in Table 2. DNA methylation of CpG islands for SFRP1, p14, p73, APC, DAPK, RASSF1A, LINE1, O6MGMT, and p16 genes was determined using specific primers for methylated (M) and unmethylated (UM) DNA. 
Waleed Seif Eldin Mohamed Mostafa, et al. Methylated genes \& antiviral therapy response

Table 2. Primers sequences and conditions of the methylation specific PCR

\begin{tabular}{|c|c|c|c|c|}
\hline Gene & Primer sequence & AT $\left({ }^{\circ} \mathrm{C}\right)$ & $\mathrm{MgCl}_{2}(\mathrm{mM})$ & No. of cycles \\
\hline \multicolumn{5}{|c|}{ SFRP $1^{17}$} \\
\hline MF & TTT AGT AAA TCG AAT TCG TTC GC & 60 & 4.5 & 40 \\
\hline MR & TAA AAT ACG CGA AAC TCC TAC G & & & \\
\hline UF & TTT TAG TAA ATT GAA TTT GTT TGT GA & 60 & 4.5 & 40 \\
\hline UR & TAA AAT ACA CAA AAC TCC TAC AAC & & & \\
\hline \multicolumn{5}{|l|}{$\mathrm{p} 14^{18}$} \\
\hline MF & GTGTTAAAGGGCGGCGTAGC & 54 & 4.5 & 35 \\
\hline$M R$ & AAAACCCTCACTCGCGACGA & & & \\
\hline UF & TTTTTGGTGTTAAAGGGTGGTGTAGT & 56 & 4.5 & 35 \\
\hline UR & CACAAAAACCCTCACTCACAACAA & & & \\
\hline \multicolumn{5}{|l|}{ p73 } \\
\hline MF & GGACGTAGCGAAATCGGGGTTC & 62 & 4.5 & 35 \\
\hline$M R$ & ACCCCGAACATCGACGTCCG & & & \\
\hline UF & AGGGGATGTAGTGAAATTGGGGTTT & 62 & 4.5 & 35 \\
\hline UR & ATCACAACCCCAAACATCAACATCCA & & & \\
\hline \multicolumn{5}{|l|}{$\mathrm{APC}^{19}$} \\
\hline MF & TATTGCGGAGTGCGGGTC & 62 & 4.5 & 35 \\
\hline$M R$ & TCAACGAACTCCCGACGA & & & \\
\hline UF & GTGTTTTATTGTGGAGTGTGGGTT & 59.2 & 4.5 & 35 \\
\hline UR & CCAATCAACAAACTCCCAACAA & & & \\
\hline \multicolumn{5}{|c|}{ DAPK $^{18}$} \\
\hline MF & GGATAGTCGGATCGAGTTAACGTC & 59 & 4.5 & 35 \\
\hline$M R$ & CCCTCCCAAACGCCGA & & & \\
\hline UF & GGAGGATAGTTGGATTGAGTTAATGTT & 59 & 4.5 & 35 \\
\hline UR & CAAATCCCTCCCAAACACCAA & & & \\
\hline \multicolumn{5}{|c|}{ RASSF1A $^{19}$} \\
\hline MF & TTCGTCGTTTAGTTTGGATTTTG & 54.4 & 4.5 & 35 \\
\hline MR & CCGATTAAACCCGTACTTCG & & & \\
\hline UF & TGTTGTTTAGTTTGGATTTTGG & 52 & 4.5 & 35 \\
\hline UR & TACAACCCTTCCCAACACAC & & & \\
\hline \multicolumn{5}{|c|}{ LINE1 $^{27,28}$} \\
\hline MF & GCGCGAGTCGAAGTAGGGC & 60 & 4.5 & 40 \\
\hline$M R$ & CTCCGACCAAATATAAAATATAATCTCG & & & \\
\hline UF & ATTTTAGTATTTTGGGAGGTCGAGGC & 60 & 4.5 & 40 \\
\hline UR & GCAATCTCGACTCACTACAAA CTCCG & & & \\
\hline \multicolumn{5}{|c|}{$\mathrm{O}_{\mathrm{MGMT}}{ }^{18}$} \\
\hline MF & TTTCGACGTTCGTAGGTTTTCGC & 56 & 3.5 & 35 \\
\hline$M R$ & GCACTCTTCCGAAAACGAAACG & & & \\
\hline UF & TTTGTGTTTTGATGTTTGTAGGTTTTTGT & 56 & 4.5 & 35 \\
\hline UR & AACTCCACACTCTTCCAAAAACAAAACA & & & \\
\hline
\end{tabular}


Table 2. Continued

\begin{tabular}{|c|c|c|c|c|}
\hline Gene & Primer sequence & AT $\left({ }^{\circ} \mathrm{C}\right)$ & $\mathrm{MgCl}_{2}(\mathrm{mM})$ & No. of cycles \\
\hline \multicolumn{5}{|l|}{$\mathrm{p} 16^{18}$} \\
\hline MF & TTATTAGAGGGTGGGGCGGATCGC & 68 & 1.5 & 33 \\
\hline MR & GACCCCGAACCGCGACCGTAA & & & \\
\hline UF & TTATTAGAGGGTGGGGTGGATTGT & 58 & 4.5 & 33 \\
\hline UR & CAACCCCAAACCACAACCATAA & & & \\
\hline
\end{tabular}

$P C R$, polymerase chain reaction; AT, annealing temperature; MF, methylated forward; MR, methylated reverse; UF, unmethylated forward; UR, unmethylated reverse.

Negative control specimens (without DNA) were included in each PCR set. PCR products were analysed on $4 \%$ ethidium bromidestained agarose gel and visualized under UV. ${ }^{17-19}$

\section{Statistical analysis}

Statistical analysis was done using IBM SPSS Statistics 21.0 (International Business Machines Corporation Company, New York, NY, USA). For categorical variables, percentages were calculated, and differences were analysed with chi square tests and Fisher's exact test when appropriate. Continuous variables were analysed as mean \pm standard deviation or median and range as appropriate. Differences among continuous variables with normal distribution were analysed by Student's $t$-test; comparison between three groups was done using Kruskel-Wallis test (non-parametric analogue for analysis of variance). $P$-value which is less than (0.05) was considered statistically significant.

\section{RESULTS}

\section{Clinico-pathological features of the patients}

The demographic, laboratory, and histopathological data of the 159 patients (81 responders and 78 non-responders) are illustrated in Table 1. No significant difference was observed between the two groups (responders and non-responders) regarding age, sex, haematological parameters, liver profile, HCV viral load. However, a significant difference was found in other variables such as BMI, Fibrosis, necroinflammatory activity, and steatosis (Table 1).

\section{HCV RNA results}

For HCV RNA levels by RT-PCR technique, there was no signifi- cant difference $(P=0.789)$ between responders $(193.000 \pm 108)$ and non-responders $(338.000 \pm 237)$ for the $159 \mathrm{CHC}$ patients before treatment (Table 1). HCV RNA results at different treatment end points and follow up of our patients were done to detect treatment response as shown in Table 3.

\section{Methylation frequency of the studied genes in plasma samples}

The methylation frequency of SFRP1, p14, p73, APC, DAPK, RASSF1A, LINE1, 6MGMT, and p16 genes for chronic HCV-4 Egyptian patients and healthy control group is shown in Table 4, Figure 1, 2 . Regarding the patients' response to antiviral therapy, the percentage of non-responders for APC, O6MGMT, RASSF1A, SFRP1, and p16 methylated genes were significantly $(P<0.05)$ higher versus responders (Table 4, Fig. 2), where it was $75.6 \%, 75.8 \%, 69.4 \%$, $63.7 \%$, and $65 \%$ versus $24.4 \%, 24.2 \%, 30.6 \%, 36.3 \%$, and $35 \%$ for APC, O6MGMT, RASSF1A, SFRP1, and p16 methylated genes respectively.

Of the 159 included patients, the most frequent methylated genes were SFRP1 (102/159), followed by p16 (100/159), RASSF1A (98/159), then LINE1 (81/159), P73 (81/159), APC (78/159), DAPK (66/159), 06MGMT (66/159), and p14 (54/159) (Fig. 1).

\section{Promotor methylation index}

It defined as the ratio between the number of methylated genes and the total number of the studied genes for each sample was calculated for all patients. ${ }^{19}$ For methylation index, no significant difference was found between responders and non-responders $(2.65 \pm 1.31$ and $2.71 \pm 1.23 ; P=0.67)$ respectively. Also, there is no significant difference between mild fibrosis (F1 and F2) and marked fibrosis ( $F 3$ and $F 4)$ except for RASSF1A $(P=0.024)$ and p16 $(P=0.03)$ methylated genes (Table 5). 
Table 3. HCV RNA of the $159 \mathrm{CHC}$ patients at different treatment end points

\begin{tabular}{|c|c|c|c|c|}
\hline HCV RNA (+/-) by RT-PCR after weeks & Non-responder $(n=78)$ & Responder $(n=81)$ & Total & $P$-value \\
\hline \multicolumn{5}{|l|}{ PCR-W12 } \\
\hline Negative & $69(46.0)$ & $81(54.1)$ & $150(100.0)$ & \multirow{3}{*}{$0.032^{*}$} \\
\hline Positive & $9(100.0)$ & $0(0.0)$ & $9(100.0)$ & \\
\hline Total & 78 (49.1) & $81(50.9)$ & 159 (100.0) & \\
\hline \multicolumn{5}{|l|}{ PCR-W24 } \\
\hline Negative & $66(44.9)$ & $81(55.1)$ & $147(100.0)$ & \multirow{3}{*}{$0.022^{*}$} \\
\hline Positive & $12(100.0)$ & $0(0.0)$ & $12(100.0)$ & \\
\hline Total & 78 (49.1) & 81 (50.9) & 159 (100.0) & \\
\hline \multicolumn{5}{|l|}{ PCR-W48 } \\
\hline Negative & $27(25.0)$ & $81(75)$ & $108(100.0)$ & \multirow{3}{*}{$<0.001^{*}$} \\
\hline Positive & $51(100.0)$ & $0(0.0)$ & $51(100.0)$ & \\
\hline Total & 78 (49.1) & 81 (50.9) & 159 (100.0) & \\
\hline \multicolumn{5}{|l|}{ PCR-W72 } \\
\hline Negative & $6(6.9)$ & $81(93.1)$ & $87(100.0)$ & \multirow{3}{*}{$<0.001^{*}$} \\
\hline Positive & $72(100.0)$ & $0(0.0)$ & 72 (100.0) & \\
\hline Total & $78(49.1)$ & $81(50.9)$ & $159(100.0)$ & \\
\hline
\end{tabular}

Values are presented as number (\%).

$H C V$, hepatitis C virus; $C H C$, chronic hepatitis C; RT-PCR, reverse transcription-polymerase chain reaction; W, weeks.

${ }^{*} P$-value $<0.05$ is considered significant.

\section{DISCUSSION}

The foremost predictors of response to interferon-based HCV therapy included both patient and viral factors. Patient factors that were associated with worse response to interferon-based therapy included male gender, older age, high BMI, advanced liver fibrosis, history of failed treatment, black race, non-CC IL28B genotype, and the presence of certain comorbid conditions, such as HIV coinfection, insulin resistance, or diabetes. Viral factors that were associated with worse response included non-genotype-2 infection, high viral load, and unfavourable viral kinetics during treatment. ${ }^{4,20}$

Some authors have revealed that hepatitis viruses infection might play a role in fast-tracking the methylation process which is involved in HCC development, and affect its response to treatment. ${ }^{6,19,21,22}$ Progression from chronic hepatic inflammation to the fibrotic/cirrhotic stage is supported by numerous core pathways, observed in other fibrotic diseases, as well as tissue- or injuryspecific pathways that are only activated in particular conditions. ${ }^{12,13}$

In an early work done by our group, ${ }^{16}$ detection of APC, FHIT, p15, p16 and E-cadherin-PM (range, 67.9-89.2\%) had been done in the plasma and tissues of 28 chronic HCV and/or HBV-associated HCC patients, with a high concordance for all studied genes. However, no significant association was found, in this study, between the methylation status of any gene and the presence of hepatitis virus infection. This was partially attributed to the small sample size in this study. Then, we assessed the contribution of methylation status to the development and progression of HCVassociated HCC and $\mathrm{CH}$ in Egyptian patients using a specific panel of genes (APC, FHIT, p15, p73, p14, p16, DAPK1, CDH1, RARb, RASSF1A, O6MGMT). ${ }^{19}$ We found that HCV infection may contribute to hepatocarcinogenesis through enhancing PM of certain genes. A panel of 4 genes (APC, p73, p14, O6MGMT) out of 11 tested genes successfully classified cases into $\mathrm{HCC}$ or $\mathrm{CH}$ with high accuracy (89.9\%), sensitivity (83.9\%) and specificity (94.7\%). A more extended confirmatory study, including 516 Egyptian patients with HCV-related liver disease (208 HCC, 108 liver cirrhosis, $100 \mathrm{CHC}$, and 100 controls), was then performed to detect PM of P14, P15, P73 and Mismatch repair gene (06MGMT) in patient's plasma by using EpiTect Methyl qPCR Array technology. ${ }^{23}$ The candidate genes selection (SFRP1, p14, p73, APC, DAPK, RASSF1A, LINE1, 06MGMT, and p16) of the present work was analyzed by the Gene Expression Profiling Interactive Analysis database. 
Table 4. Methylation frequency of the studied genes for 159 Egyptian patients with chronic genotype 4 hepatitis $C$ in relation to treatment response

\begin{tabular}{|c|c|c|c|c|c|}
\hline \multirow[b]{2}{*}{ Methylation status } & \multicolumn{2}{|c|}{ Response to treatment } & \multirow[b]{2}{*}{ Total $(n=159)$} & \multirow[b]{2}{*}{ Control $(n=100)$} & \multirow[b]{2}{*}{$P$-value } \\
\hline & $\begin{array}{c}\text { Non-responders } \\
(n=78 ; 49.1 \%)\end{array}$ & $\begin{array}{c}\text { Responders } \\
(n=81 ; 50.9 \%)\end{array}$ & & & \\
\hline \multicolumn{6}{|l|}{ SFRP1 } \\
\hline M & $65(63.7)$ & $37(36.3)$ & $102(64.2)$ & $5(5.0)$ & $0.043^{*}$ \\
\hline U & $13(22.8)$ & $44(77.2)$ & $57(35.8)$ & $95(95.0)$ & \\
\hline \multicolumn{6}{|l|}{ p14 } \\
\hline M & $27(50.0)$ & $27(50.0)$ & $54(34.0)$ & $6(6.0)$ & 0.930 \\
\hline U & $51(48.6)$ & $54(51.4)$ & $105(66.0)$ & $94(94.0)$ & \\
\hline \multicolumn{6}{|l|}{ p73 } \\
\hline M & $45(55.6)$ & $36(44.4)$ & $81(50.9)$ & $4(4.0)$ & 0.328 \\
\hline U & $33(42.3)$ & $45(57.7)$ & $78(49.1)$ & $96(96.0)$ & \\
\hline \multicolumn{6}{|l|}{ APC } \\
\hline M & $59(75.6)$ & $19(24.4)$ & $78(49.1)$ & $5(5.0)$ & $0.02^{*}$ \\
\hline U & $19(23.5)$ & $62(76.5)$ & $81(50.9)$ & $95(95.0)$ & \\
\hline \multicolumn{6}{|l|}{ DAPK } \\
\hline M & $24(36.4)$ & $42(63.6)$ & $66(41.5)$ & $7(7.0)$ & 0.097 \\
\hline U & $54(58.1)$ & $39(41.9)$ & $93(58.5)$ & $93(93.0)$ & \\
\hline \multicolumn{6}{|l|}{ RASSF1A } \\
\hline M & $68(69.4)$ & $30(30.6)$ & $98(61.6)$ & $5(5.0)$ & $0.031^{*}$ \\
\hline U & $10(22.0)$ & $51(78.0)$ & $61(38.4)$ & $94(94.0)$ & \\
\hline \multicolumn{6}{|l|}{ LINE1 } \\
\hline M & $46(56.8)$ & $35(43.2)$ & $81(50.9)$ & $4(4.0)$ & 0.37 \\
\hline U & $32(41.0)$ & $46(59.0)$ & $78(49.1)$ & $96(96.0)$ & \\
\hline \multicolumn{6}{|l|}{ O6MGMT } \\
\hline M & $50(75.8)$ & $16(24.2)$ & $66(41.5)$ & $7(7.0)$ & $0.021^{*}$ \\
\hline U & $28(23.7)$ & $65(76.3)$ & $93(58.5)$ & $93(93.0)$ & \\
\hline \multicolumn{6}{|l|}{ p16 } \\
\hline M & 65 (65.0) & $35(35.0)$ & $100(62.9)$ & $6(6.0)$ & $0.04^{*}$ \\
\hline U & $13(22.0)$ & $46(78.0)$ & 59 (37.1) & $94(94.0)$ & \\
\hline
\end{tabular}

Values are presented as number (\%).

$M$, methylated; UM, unmethylated.

${ }^{*} P$-value $<0.05$ is considered significant.

In the current study, significant efforts had been done to elucidate the role of PM to the response to antiviral therapy and its contribution to the development of fibrosis using some hepatocarcinogenesis-related genes. Percentage of non-responders for APC, O6MGMT, RASSF1A, SFRP1, and p16 methylated genes were significantly $(P<0.05)$ higher than those in responders. The most frequent methylated genes in the $159 \mathrm{CHC}$ patients was SFRP1 (102/159), followed by p16 (100/159), RASSF1A (98/159), then LINE1 (81/159), P73 (81/159), APC (78/159), DAPK (66/159),
O6MGMT (66/159), and p14 (54/159). In a previous study done by lyer et al. ${ }^{16}$, they detected a high frequency of 5 methylated genes (APC, FHIT, p15, p16 and E-cadherin) which ranged from 67.9\% to $89.2 \%$ in the plasma and tissues of 28 chronic HCV and/or HBV-associated HCC patients. Although, no significant association was found in his study between the methylation status of any gene and the presence of hepatitis virus infection which could be attributed to the small sample size. Also, in a previous study done by our group, ${ }^{7}$ we assessed the contribution of methylation status 


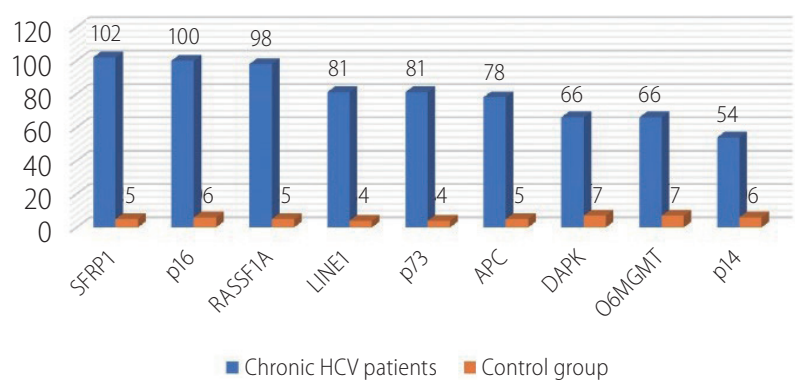

Figure 1. Frequency of the methylated genes in chronic hepatitis $C$ patients and healthy control group. HCV, hepatitis C virus.

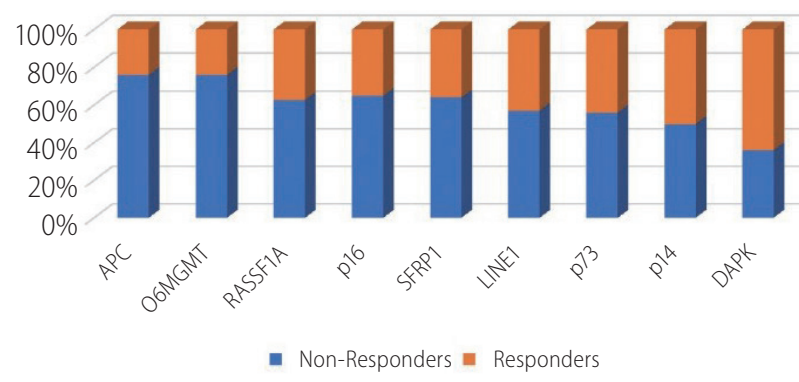

Figure 2. Percentage of non-responders and responders of the studied methylated genes in chronic hepatitis c patient.

Table 5. Correlation between methylation of the studied genes and degree of fibrosis

\begin{tabular}{lccc}
\hline Methylated gene & Mild fibrosis (F1 \& F2) (n=120; 75.5\%) & Marked fibrosis (F3 \& F4) (n=39; 24.5\%) & P-value \\
\hline SFRP1 & $47 / 102(46.0 \%)$ & $55 / 102(54.0 \%)$ & 0.68 \\
P14 & $26 / 54(48.2 \%)$ & $28 / 54(51.8 \%)$ & 0.73 \\
P73 & $36 / 81(44.5 \%)$ & $45 / 81(55.5 \%)$ & 0.69 \\
APC & $36 / 78(46.2 \%)$ & $42 / 78(53.8 \%)$ & 0.45 \\
DAPK & $29 / 66(43.9 \%)$ & $37 / 66(56.1 \%)$ & 0.36 \\
RASSF1A & $67 / 98(68.4 \%)$ & $31 / 98(31.6 \%)$ & $0.024^{*}$ \\
LINE1 & $35 / 81(43.2 \%)$ & $46 / 81(56.8 \%)$ & 0.35 \\
O6MGMT & $36 / 66(54.4 \%)$ & $30 / 66(45.6 \%)$ & 0.68 \\
P16 & $62 / 100(62.0 \%)$ & $38 / 100(38.0 \%)$ & $0.03^{*}$ \\
\hline PP-Va
\end{tabular}

${ }^{*} P$-value $<0.05$ is considered significant.

to the development and progression of HCV-associated HCC and $\mathrm{CH}$ in Egyptian patients using a specific panel of genes (APC, FHIT, p15, p73, p14, p16, DAPK1, CDH1, RARb, RASSF1A, 06MGMT). We found that HCV infection may contribute to hepatocarcinogenesis through enhancing the promotor methylation of certain genes. On the other hand, Huang et al., ${ }^{14}$ determined whether methylation status in plasma could be employed for monitoring the multistep carcinogenesis, multiplex MSP was applied to assay the methylation status for p16, SFRP1, and LINE1 in plasma specimens of 119 HCC patients, 105 LC patients, 52 patients with benign lesions and 50 healthy people. Therefore, Huang et al. ${ }^{14}$ found that the modification in the expression of p16, SFRP1, and LINE1 genes might be involved in the process of hepatocarcinogenesis.

The present work has shown that the most frequent methylated genes in the 159 CHC patients were SFRP1, p16, RASSF1A, APC, and O6MGMT, where they were 102 (64.2\%), 100 (62.9\%), 98 $(61.6 \%), 78(49.1 \%)$, and $66(41.5 \%)$, respectively. This finding does not go well with the previous study done by Zekri et al. ${ }^{7}$ where they found that 06MGMT had the highest methylation fre- quency among HCV infected patients (64.2\%) followed by $p 73$ (50.9\%), APC (49.1\%), RASSF1A/DAP-kinase (41.5\%), and p14 $(34 \%)$. This discrepancies in results might be attributed to a small sample size of his study, where it was done on 53 CHC cases comparing to 159 chronic HCV patients and 100 healthy controls of the current work.

For the PM of the studied genes and degree of fibrosis, 67/98 (68.4\%) cases of RASSF1A methylated gene $(P=0.0 .024)$ and $62 / 100(62 \%)$ cases of p16 methylated gene $(P=0.03)$ were associated with mild fibrosis. This finding was close to the results that found by Zekri et al. ${ }^{7}$ where they stated that only PM of the RASSF1A gene was significantly associated with mild fibrosis in the studied patients $(P=0.0 .019)$. However, his study was done on six genes (p14, p73, APC, DAPK, RASSF1A, and 06MGMT) of 53 chronic HCV patients while our study was applied on nine genes (SFRP1, p14, p73, APC, DAPK, RASSF1A, LINE1, 06MGMT, and p16) of $159 \mathrm{CHC}$ patients. This finding might be explained by the fact that DNA methylation modification is played by the HCV core protein which inhibit the expression of the CDKN2A gene, that encodes for p16INK (inhibitor of cell proliferation) by up-regulat- 
ing the methyltransferases DNMT1 and DNMT3b. ${ }^{24,25}$ Moreover, HCV core protein also increases the methylation of RASSF1A promoter, a negative regulator of the Ras pathway, by inducing the histone methyltransferase SMYD3. ${ }^{25,26}$ Therefore, our results provide an evidence for the role of RASSF1A, and p16 genes in the induction of fibrogenesis in chronic HCV patients.

In conclusion, the PM of SFRP1, APC, RASSF1A, O6MGMT, and p16 genes increases in $\mathrm{CHC}$ patients. These methylated genes can significantly affect patients' response to antiviral treatment, whereas RASSF1A and p16 genes are involved in the process of fibrogenesis and possibly will have a role in the distinction between mild and marked fibrosis in those patients.

\section{Ethics approval and consent to participate}

This study was performed in compliance with relevant laws and institutional guideline and in accordance with the ethical standards of the Declaration of Helsinki. The Institutional Review Board (IRB) of the $\mathrm{NCl}$ approved the protocol. Informed written consent was obtained from all patients and individuals enrolled in the study.

\section{Author's contribution}

WSM conceived and designed the study with inputs from DAO. WSM and MHS were responsible for the supervision and coordination of the project. ZFA and MNI performed most of the in vitro experiments. DAO, ZFA, YMS, and HES collected the clinical specimens. WSM performed statistical analysis of the data. The first draft of the manuscript was written by WSM and DAO then MHS, YMS, HES, MNI contributed to revise and review the manuscript. All authors read and approved the final manuscript before submission.

\section{Conflicts of Interest}

The authors have no conflicts to disclose.

\section{REFERENCES}

1. Zetterman RK. Evaluating the patient with abnormal liver tests. Medscape web site, <https://www.medscape.com/viewarticle/710045_2>. Accessed 8 Oct, 2009.

2. Nguyen $M H$, Keeffe EK. Prevalence and treatment of hepatitis $C$ virus genotypes 4, 5, and 6. Clin Gastroenterol Hepatol 2005;3(10 Suppl 2):S97-S101.

3. Strader DB, Wright T, Thomas DL, Seeff LB; American Association for the Study of Liver Diseases. Diagnosis, management, and treatment of hepatitis C. Hepatology 2004;39:1147-1171.

4. Manns MP, Wedemeyer $H$, Cornberg M. Treating viral hepatitis C: efficacy, side effects, and complications. Gut 2006;55:1350-1359.

5. Yu J, Ni M, Xu J, Zhang H, Gao B, Gu J, Chen J, et al. Methylation profiling of twenty promoter- $\mathrm{CpG}$ islands of genes which may contribute to hepatocellular carcinogenesis. BMC Cancer 2002;2:29.

6. Okamoto Y, Shinjo K, Shimizu Y, Sano T, Yamao K, Gao W, et al. Hepatitis virus infection affects DNA methylation in mice with humanized livers. Gastroenterology 2014;146:562-572.

7. Zekri AN, Raafat AM, Elmasry S, Bahnassy AA, Saad Y, Dabaon HA, et al. Promotor methylation: does it affect response to therapy in chronic hepatitis C (G4) or fibrosis? Ann Hepatol 2014;13:518-524.

8. Anwar SL, Lehmann U. DNA methylation, microRNAs, and their crosstalk as potential biomarkers in hepatocellular carcinoma. World J Gastroenterol 2014;20:7894-7913.

9. Dong Y, Wang A. Aberrant DNA methylation in hepatocellular carcinoma tumor suppression (review). Oncol Lett 2014;8:963-968.

10. Herbst A, Rahmig K, Stieber $P$, Philipp A, Jung $A$, Ofner $A$, et al. Methylation of NEUROG1 in serum is a sensitive marker for the detection of early colorectal cancer. Am J Gastroenterol 2011;106:11101118.

11. Huang W, Li T, Yang W, Chai X, Chen K, Wei L, et al. Analysis of DNA methylation in plasma for monitoring hepatocarcinogenesis. Genet Test Mol Biomarkers 2015;19:295-302.

12. Pinzani M, Rombouts K, Colagrande S. Fibrosis in chronic liver diseases: diagnosis and management. J Hepatol 2005;42 Suppl(1):S22S36.

13. Friedman SL, Sheppard D, Duffield JS, Violette S. Therapy for fibrotic diseases: nearing the starting line. Sci Transl Med 2013;5:167sr1.

14. Huang Y, Wei L, Zhao RC, Liang WB, Zhang J, Ding XQ, et al. Predicting hepatocellular carcinoma development for cirrhosis patients via methylation detection of heparocarcinogenesis-related genes. J Cancer 2018;9:2203-2210.

15. Halfon $P$, Bourlière $M$, Pénaranda $G$, Khiri $H$, Ouzan D. Real-time $P C R$ assays for hepatitis $\mathrm{C}$ virus (HCV) RNA quantitation are adequate for clinical management of patients with chronic HCV infection. J Clin Microbiol 2006;44:2507-2511.

16. Iyer P, Zekri AR, Hung CW, Schiefelbein E, Ismail K, Hablas A, et al. Concordance of DNA methylation pattern in plasma and tumor DNA of Egyptian hepatocellular carcinoma patients. Exp Mol Pathol 2010;88:107-111.

17. Lo PK, Mehrotra J, D'Costa A, Fackler MJ, Garrett-Mayer E, Argani $P$, et al. Epigenetic suppression of secreted frizzled related protein 1 (SFRP1) expression in human breast cancer. Cancer Biol Ther 2006;5:281-286

18. Gutierrez MI, Siraj AK, Bhargava M, Ozbek U, Banavali S, Chaudhary $M A$, et al. Concurrent methylation of multiple genes in childhood 
Waleed Seif Eldin Mohamed Mostafa, et al. Methylated genes \& antiviral therapy response

ALL: correlation with phenotype and molecular subgroup. Leukemia 2003;17:1845-1850.

19. Zekri AR, Bahnassy AA, Shoeab FE, Mohamed SW, El-Dahshan DH, Ali FT, et al. Methylation of multiple genes in hepatitis $C$ virus associated hepatocellular carcinoma. J Adv Res 2014;5:27-40.

20. Papatheodoridis G, Manolakopoulos S, Kapatais A, Sinakos E, Elefsiniotis I, Goulis J, et al. Predictors of sustained virological response (SVR) in patients with advanced chronic hepatitis $\mathrm{C}(\mathrm{CHC})$ treated with current direct acting antiviral(s) (DAA). Heraclis: Hellenic multicenter real-life cohort study. Gastroenterology 2017;152:S1093.

21. Rongrui L, Na H, Zongfang L, Fanpu J, Shiwen J. Epigenetic mechanism involved in the HBV/HCV-related hepatocellular carcinoma tumorigenesis. Curr Pharm Des 2014;20:1715-1725.

22. Wijetunga NA, Pascual M, Tozour J, Delahaye F, Alani M, Adeyeye M, et al. A pre-neoplastic epigenetic field defect in HCV-infected liver at transcription factor binding sites and polycomb targets. Oncogene 2017;36:2030-2044.

23. Zekri Ael-R, Nassar AA, El-Din El-Rouby MN, Shousha HI, Barakat $A B, E l-D e s o u k y E D$, et al. Disease progression from chronic hepatitis $C$ to cirrhosis and hepatocellular carcinoma is associated with increasing DNA promoter methylation. Asian Pac J Cancer Prev 2013;14:6721-6726.

24. Park SH, Lim JS, Lim SY, Tiwari I, Jang KL. Hepatitis C virus core protein stimulates cell growth by down-regulating p16 expression via DNA methylation. Cancer Lett 2011;310:61-68.

25. Vescovo T, Refolo G, Vitagliano G, Fimia GM, Piacentini M. Molecular mechanisms of hepatitis $C$ virus-induced hepatocellular carcinoma. Clin Microbiol Infect 2016;22:853-861.

26. Guo N, Chen R, Li Z, Liu Y, Cheng D, Zhou Q, et al. Hepatitis C virus core upregulates the methylation status of the RASSF1A promoter through regulation of SMYD3 in hilar cholangiocarcinoma cells. Acta Biochim Biophys Sin (Shanghai) 2011:43:354-361.

27. Santourlidis S, Ghanjati F, Beermann A, Hermanns T, Poyet C. IDLNMSP: idiolocal normalization of real-time methylation-specific PCR for genetic imbalanced DNA specimens. Biotechniques 2016;60:8487.

28. Erichsen L, Beermann A, Arauzo-Bravo MJ, Hassan M, Dkhil MA, AlQuraishy $\mathrm{S}$, et al. Genome-wide hypomethylation of LINE-1 and Alu retroelements in cell-free DNA of blood is an epigenetic biomarker of human aging. Saudi J Biol Sci 2018;25:1220-1226. 